\title{
Correction to: The Multicriterial Approach to the Problem of Demarcation
}

\author{
Damian Fernandez-Beanato $^{1,2}$ (D)
}

Published online: 1 September 2020

(c) Springer Nature B.V. 2020

\section{Correction to: Journal for General Philosophy of Science https://doi.org/10.1007/s10838-020-09507-5}

The Editors of JGPS regret that the corrections to this article have made two formulations misleading for the reader:

1. In the original publication, the last sentence of the Introduction is: "Section 5 also indicates the width of practical applicability that a SD is achieved through the completion of this project.". This sentence should be replaced by: "Section 5 also indicates the width of practical applicability that a SD achieved through the completion of this project would enjoy.".

2. In the original publication, in Section 2.2, point 2 of the list of Kuhn's selected group of "values" reads: "consistency_internal and external, the latter being compatible with other theories contemporaneously accepted;". This should be replaced by: "consistency-internal and external, the latter being compatibility with other theories contemporaneously accepted;".

Publisher's Note Springer Nature remains neutral with regard to jurisdictional claims in published maps and institutional affiliations.

The original article can be found online at https://doi.org/10.1007/s10838-020-09507-5.

Damian Fernandez-Beanato

damian.fernandezbeanato@bristol.ac.uk; damianbeanato@gmail.com

1 University of Bristol, Bristol, UK

2 Bristol, UK 